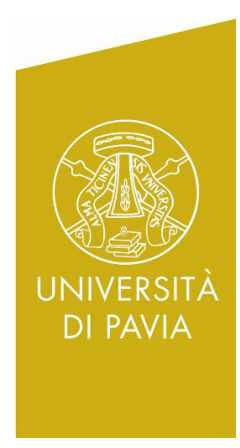

Department of Economics and Management DEM Working Paper Series

\title{
Dynamic hierarchical models for monetary transmission
}

\author{
Paolo Giudici \\ (Università di Pavia) \\ Laura Parisi \\ (Università di Pavia) \\ \# 112 (11-15) \\ Via San Felice, 5 \\ I-27100 Pavia \\ http://epmq.unipv.eu/site/home.html
}

November 2015 


\title{
Dynamic hierarchical models for monetary transmission*
}

\author{
Paolo Giudici, Laura Parisi \\ University of Pavia \\ paolo.giudici@unipv.it, laura.parisi01@universitadipavia.it
}

\begin{abstract}
Monetary policies, either actual or perceived, cause changes in monetary interest rates. These changes impact the economy through financial institutions, which react to changes in the monetary rates with changes in their administered rates, on both deposits and lendings.

The dynamics of administered bank interest rates in response to changes in money market rates is thus essential to examine the impact of monetary policies on the economy. Chong et al. (2006) proposed an error correction model to study such impact, using data previous to the recent financial crisis. Parisi et al. (2015) analyzed the Chong error correction model, extended it and proposed an alternative, simpler to interpret, one-equation model, and applied it to the recent time period, characterized by close-to-zero monetary rates.

In this paper we extend the previous models in a dynamic sense, modelling monetary transmission effects by means of dynamic linear models.

The main contribution of this work consists in a novel methodology that provides a mechanism to identify the time dynamics of interest rates, linking them to monetary rates and to macroeconomic, countryspecific variables. In addition, it introduces a predictive performance
\end{abstract}

*Presented at: XXIV International Rome Conference on Money, Banking and Finance, Rome; XI Convention of the Italian Association of Financial Risk Management, Milan. 
assessment methodology, which allows to compare the proposed models on a fair ground.

From an applied viewpoint, the paper applies the proposed models to interest rates on different loans, showing how the monetary policy and the specific situation of each country differently impact lendings, not only across countries but also across time.

Keywords: Forecasting Bank Interest Rates, Dynamic Time Series Models, Hierarchical Models.

\section{Introduction}

Monetary policies, such as variations in the official rate or liquidity injections, cause changes in monetary interest rates. These changes impact the economy mainly in an indirect way, through financial institutions, which react to changes in the monetary rates with changes in their administered rates, on both deposits and lendings.

The dynamics of administered bank interest rates in response to changes in money market rates is essential to examine the impact of monetary policies on the economy. This dynamics has been the subject of an extensive literature; the available studies differ, depending on the used models, the period under analysis and the geographical reference.

The relationship between market rates and administered rates is a complicated one and the evidence presented, thus far, is mixed and inconclusive (for an overview see, e.g., Borio and Zhu, 2012).

Hannan and Berger (1991), for example, examine the deposit rate setting behaviour of commercial banks in the United States and find that (a) banks in more concentrated markets exhibit greater rates rigidity; (b) larger banks exhibit less rates rigidity; and (c) deposit rates are more rigid upwards than downwards. Scholnick (1996), similarly, finds that deposit rates are more rigid when they are below their equilibrium level than when they are above; his finding on lending rate adjustment, however, is mixed. Heffernan (1997) examines how the lending and deposit rates of four banks and three building societies respond to changes in the base rate set by the Bank of England

and finds that (a) there is very little evidence on the asymmetric nature of adjustments in both the deposit and lending rates, (b) there is no systematic difference in the administered rate pricing dynamics of banks and building so- 
cieties, and (c) the adjustment speed for deposit rates is, on average, roughly the same as that for loan rates.

The empirical evidence contained in more recent papers on the same issue, such as Ballester et al. (2009), Chong et al. (2006), Demirguc-Kunt and Huizinga (1999), Flannery et al. (1984), Maudos et al. (2004), Maudos et al. (2009), can be summarized in the following points: (a) bank rates react with a partial and delayed change to changes in the monetary rates; (b) the speed and the degree to which they follow these changes present substantial differences between the various categories of banking products and between different countries.

The previous conclusions have been obtained for a relatively stable time period, previous to the emergence of the recent financial crisis.

After 2008, however, we have observed substantial changes. From a macroeconomic viewpoint, monetary interest rates are now, in most developed economies, close to zero, or negative; from a microeconomic viewpoint, bank management has changed substantially, for the compression of interest margins and for the increase in regulatory capital requirements. The effects of the previous changes on the transmission of monetary policies have not been yet fully investigated. In particular, the current state of close-to-zero interest rates is of particular relevance, and, to our knowledge, Parisi et al. (2015) is the only paper that has concentrated on this topic, in a classical linear regression framework.

In the Eurozone, the sovereign debt crisis has increased the heterogeneity of financial conditions in the Eurozone, making the transmission of the monetary impulse less uniform across euro-area countries (see, e.g., Draghi, 2012). In particular, Neri (2014) has demonstrated that sovereign debt tensions have had a substantial impact in the transmission mechanism of monetary rates in peripheral countries, while such a change can not be detected in core ones. However, the analysis proposed by Neri (2014) only concentrates on the impact of sovereign bond interest rates on bank administered rates within a static framework, without considering time-varying relationships as well as different macroeconomic indicators.

The aim of this paper is to broaden the models of Neri (2014) and Parisi et al. (2015), introducing a hierarchical time dynamics able (a) to capture the evolving relationship between bank rates and monetary rates, taking into account correlation effects between different kinds of loans within each country; (b) to understand how country-specific macroeconomic factors may have differently affected the monetary transmission across european countries 
and how such relationships have changed over time; (c) to provide better results in terms of both in-sample tests and out-of-sample predictions.

The proposed methods are applied to data from the recent period (20032014), for core (France, Germany, the Netherlands) and peripheral (Ireland, Italy, Portugal, Spain) countries.

The effect of monetary policies is studied for three categories of loans: (a) loans to non-financial corporates up to 1 Mln euros; (b) loans to non-financial corporates over 1 Mln euros; (c) loans to households for mortgages.

The paper is structured as follows. Section 2 describes the proposed models and, in particular: Section 2.1 describes the theoretical framework; Section 2.2 introduces the new proposed models, with Subsection 2.2 .1 concentrating on seemingly unrelated dynamic models and Subsection 2.2.2 describing hierarchical dynamic processes. Section 2.3 provides the parameters estimation techniques and the predictive performance environment used to compare the models. Section 3 shows the empirical evidence obtained from the application of the models and, in particular: Section 3.1 describes the available data; Section 3.2 presents the results obtained with the seemingly unrelated dynamic model; Section 3.3 presents the results obtained with the hierarchical dynamic model; Section 3.4 shows predictive performances and compares the models. Finally, Section 4 concludes with some final remarks.

\section{Methodology}

\subsection{Theoretical Framework}

In line with the contribution of Chong et al. (2006), the relationship between monetary rates and administered bank rates can be analyzed with the Error Correction Model (ECM), following the procedure proposed by Engle and Granger (1987). The model is based on two equations. A long-run relationship, which provides a measure of how a change in the monetary rate is reflected in the bank rate. A short-run equation, which includes an error correction term, which evaluates variations of the administered interest rates as a function of variations in the monetary rates.

Parisi et al. (2015) analyzed and extended Chong et al. (2006), by proposing an alternative one-equation model. More precisely, they assumed that bank interest rates depend on their previous level, to allow for a slow and partial reaction of bank rates to monetary rates changes. Thus, they 
modeled bank administered interest rates as a function of monetary rates, their variations and the previous level of bank rates. Their complete model, that in the next Sections will be called the Parisi et al. model, can be formalized as follows:

$$
B R_{t}=k+\beta \cdot M R_{t-1}+\gamma \cdot \Delta M R_{t}+\delta \cdot B R_{t-1}+\epsilon_{t} .
$$

In equation (2.1) $B R_{t}$ and $M R_{t}$ represent, respectively, the bank administered rates and the monetary rates at time $t ; \beta$ is a regression coefficient that gives a measure of the extent of the monetary rate transmitted on bank rates in a long-term perspective; $\gamma$ is the coefficient that explains the influence of the variations of monetary rates on the bank rates levels; $\delta$ weights the autoregressive component $B R_{t-1} ; k$ is a constant that summarizes all other factors that, in addition to the dynamics described by the regressors, may affect the transmission mechanism of the monetary policy on bank rates as, for example, the market power and the efficiency of a bank; finally, $\epsilon_{t}$ is the error term.

Neri (2014) proposed a model that, differently from Chong et al. (2006) and Parisi et al. (2015), explains bank rate dynamics as a function of exogenous variables, different from the monetary rate. More precisely, he establishes a relationship between lending rates $\left(B R_{j, t}^{k}\right.$, with $j=$ country, $k=$ type of loan) and the spread between the yields on government bonds and the 10-year swap rate $\left(R_{j, t-1}^{10}-R_{t-1}^{10, s w a p}\right)$, as follows

$B R_{j, t}^{k}=\overline{B R}_{j}^{k}+\alpha_{1} D_{t}^{c r i s i s}+\alpha_{2} D_{t}^{2008}+\alpha_{3} R_{t-1}^{o v}+\alpha_{4}\left(M R_{t-1}^{3 m}-M R_{t-1}^{o v}\right)+\alpha_{5}\left(R_{j, t-1}^{10}-R_{t-1}^{10, s w a p}\right)+\alpha_{6} Y_{t-1}^{k}+\alpha_{7} B R_{j, t-1}^{k}+\epsilon_{t}$,

where $D_{t}^{\text {crisis }}$ and $D_{t}^{2008}$ are dummy variables that become one during Lehman Brothers and 2008 crisis, $M R_{t-1}^{3 m}-M R_{t-1}^{o v}$ represents the spread between three-months Euribor and the EONIA, and $Y_{t-1}^{k}$ is a confidence indicator. A similar approach has been followed also by De Santis and Surico (2013).

While both (2.1) and (2.2) extend Chong et al. (2006), they still do not account for time-dependent parameters and, therefore, they need to introduce time-windows and dummy variables in order to consider changes in time.

In this paper, we overcome this issue by introducing dynamic models, which not only allow to derive time-varying relationships without imposing ex-post dummies, but also enable the prediction of future values.

We also merge together the models (2.1) and (2.2) by considering a dynamic hierarchical process, composed by two stages. The first one models 
bank rates on loans as a time-varying function of monetary rates by using seemingly unrelated regressions, thus emphasizing how monetary transmission has changed over time in different geographical ares, starting from the assumption that interest rates on different loans are correlated. The second one explains the residual component obtained by the first stage, by means of multiple dynamic models, relating it to country-specific macroeconomic indicators, again in a time-varying framework.

\subsection{The proposed models}

\subsubsection{Seemingly Unrelated Dynamic Linear Models}

We have anticipated that the relationship between bank rates and monetary rates has radically changed during the last years, reaching a situation of almost-zero monetary rates. In order to better analyze how bank rates react to changes in monetary rates, and to understand how this reaction changes over time, simple linear models can be enriched with a dynamic structure.

Dynamic linear models are a particular class of state-space models, in which the regression coefficients are allowed to vary over time: for an introduction, see, e.g., Petris et al. (2009). More formally, since we consider $N$ different countries and three different kinds of loans, let us introduces two sets, $V=\{1, \ldots, N\}$ and $W=\{1,2,3\}$, and let the index $i$ be $i \in W \times V$. The dynamic equations can thus be expressed as follows:

$$
\left\{\begin{array}{lll}
B R_{t}^{i}=k_{t}^{i}+\beta_{t}^{i} M R_{t}+\epsilon_{t}^{i}, & \epsilon_{t}^{i} \sim N\left(0, \sigma_{\epsilon^{i}}^{2}\right) \\
k_{t}^{i}=k_{t-1}^{i}+\omega_{k, t}^{i}, & \omega_{k, t}^{i} \sim N\left(0, \sigma_{\omega^{i}, k^{i}}^{2}\right) \\
\beta_{t}^{i}=\beta_{t-1}^{i}+\omega_{\beta, t}^{i}, & \omega_{\beta, t}^{i} \sim N\left(0, \sigma_{\omega^{i}, \beta^{i}}^{2}\right),
\end{array}\right.
$$

where the quantities $\left(\epsilon_{t}^{i}, \omega_{k, t}^{i}, \omega_{\beta, t}^{i}\right)$, for $t=1, \ldots, T$, are assumed to be independent from each other.

Equation (2.3) can be rewritten in a compact form: by using the following substitutions,

$$
\Theta_{t}^{i}=\left[\begin{array}{c}
k_{t}^{i} \\
\beta_{t}^{i}
\end{array}\right], \quad F_{t}=\left[\begin{array}{c}
1 \\
M R_{t}
\end{array}\right], \quad G=\left[\begin{array}{ll}
1 & 0 \\
0 & 1
\end{array}\right], \quad W_{t}^{i}=\left[\begin{array}{c}
\omega_{k, t}^{i} \\
\omega_{\beta, t}^{i}
\end{array}\right],
$$

(2.3) becomes: 


$$
\left\{\begin{array}{l}
B R_{t}^{i}=F_{t}^{T} \Theta_{t}^{i}+\epsilon_{t}^{i}, \\
\Theta_{t}^{i}=G \Theta_{t-1}^{i}+W_{t}^{i} .
\end{array}\right.
$$

The previous model consists of $N \times 3$ independent equations, each of them referred to a different kind of loan in a specific country. Such independence hypothesis can be relaxed, since we assume that, within each country, interest rates on different kinds of loans similarly react to changes in monetary rates. In order to take into account the hypothesis that, within each of the $N$ countries but not across them, $B R_{t}^{j}$ (with $j \in W$ ) follow the same type of dynamics, we introduce seemingly unrelated dynamic regressions.

More formally, let us consider the state vector $\Theta_{t}^{h}=\left(k_{t}^{1, h}, k_{t}^{2, h}, k_{t}^{3, h}, \beta_{t}^{1, h}, \beta_{t}^{2, h}, \beta_{t}^{3, h}\right)^{T}$, with $h \in V$ and $\{1,2,3\} \in W$. Similarly to equation (2.3), the $j$ th component of bank rates, within each country, follows a dynamic linear model:

$$
\left\{\begin{array}{l}
B R_{t}^{j}=F_{t} \theta_{t}^{j}+\epsilon_{t}^{j} \\
\theta_{t}^{j}=G \theta_{t-1}^{j}+\omega_{t}^{i}
\end{array}\right.
$$

where $\theta_{t}^{j}=\left(k_{t}^{j}, \beta_{t}^{j}\right)^{T}$ for $j=1,2,3$ and $h$ fixed. The seemingly unrelated dynamic regression for bank rates, for each country $h=1, \ldots, N$, can thus be derived as:

$$
\begin{cases}B R_{t}^{h}=\left(F_{t}^{T} \otimes I_{3}\right) \Theta_{t}^{h}+\epsilon_{t}^{h}, & \epsilon_{t}^{h} \sim N(0, V) \\ \Theta_{t}^{h}=\left(G \otimes I_{3}\right) \Theta_{t-1}^{h}+w_{t}^{h}, & w_{t}^{h} \sim N(0, W),\end{cases}
$$

where, again, $F_{t}=\left[\begin{array}{c}1 \\ M R_{t}\end{array}\right]$ and $G=I_{2}$. Furthermore, since we want the levels $k_{t}$ and the slopes $\beta_{t}$ to evolve independently, we consider $W$ as a block-diagonal matrix, whose two blocks $\left(W_{k}, W_{\beta}\right)$ can be obtained through (2.3).

\subsubsection{Hierarchical Dynamic Models}

Dynamic linear models are very adaptive to past data, since the time-dependent parameter $k_{t}$, which describe the dynamic levels of bank rates, moves to capture most of the variability unexplained by the regressors, thus becoming, de facto, a latent explanatory variable (factor). It is interesting to explain 
such latent variable $k_{t}$ through a set of regressors, again in a dynamic framework. The model proposed in (2.6) can be enriched with a further stage, thus becoming a hierarchical dynamic model, specified by the following:

$$
\left\{\begin{array}{lrl}
B R_{t}^{h}=\left(F_{B R, t}^{T} \otimes I_{3}\right) \Theta_{t}^{h}+\epsilon_{t}^{h}, & \epsilon_{t}^{h} \sim N\left(0, V_{B R}\right) \\
\Theta_{t}^{h}=\left(F_{\theta, t}^{h}\right)^{T} \Gamma_{t}^{j, h}+v_{t}^{j, h}, & v_{t}^{j, h} \sim N\left(0, V_{\theta}\right) \\
\Gamma_{t}^{j, h}=G_{t} \Gamma_{t-1}^{j, h}+w_{t}^{j, h}, & w_{t}^{j, h} \sim N(0, W),
\end{array}\right.
$$

where

$$
F_{B R, t}=\left[\begin{array}{c}
1 \\
M R_{t}
\end{array}\right], \quad F_{\theta, t}^{h}=\left[\begin{array}{c}
1 \\
X_{1, t}^{h} \\
\vdots \\
X_{p, t}^{h}
\end{array}\right], \quad \Gamma_{t}^{j, h}=\left[\begin{array}{c}
\alpha^{j, h} \\
\gamma_{1, t}^{j, h} \\
\vdots \\
\gamma_{p, t}^{j, h}
\end{array}\right], \quad G=I_{p+1}
$$

being the vector $X=\left(X_{1, t}^{h}, \ldots, X_{p, t}^{h}\right)$ an ensemble of country-specific economic variables. From equation (2.7) it is clear that the state vector $\Theta_{t}^{h}$, derived through the seemingly unrelated dynamic regression, is itself modeled by a multiple dynamic linear model. This allows to understand which are the main economic country-specific components able to describe the dynamics of the bank rates not explained by the monetary rates. It can also be used to understand the elasticity of the slope coefficient that relates monetary to bank rates.

\subsection{Parameter Estimation and Model Adequacy}

All the parameters included in both state vectors $\Theta_{t}^{h}$ and $\Gamma_{t}^{h}$ have to be estimated through a two-stages process, according to the hierarchical structure introduced in (2.7).

As previously described, the first stage consists of a double step: a dynamic model, which provides the estimated parameters $\hat{\Theta}$ and their variances, through which we can obtain the final estimation $\Theta$. According to Petris et al. (2009), we can define the following:

$$
\left\{\begin{array}{l}
f_{t}=\mathbb{E}\left(B R_{t} \mid \mathcal{D}_{t-1}\right), \\
Q_{t}=\operatorname{Var}\left(B R_{t} \mid \mathcal{D}_{t-1}\right),
\end{array}\right.
$$


where $\mathcal{D}_{t-1}$ denotes the information provided by the first $t-1$ observations $B R_{1}, \ldots, B R_{t-1}$. In such a way the log-likelihood can be derived, as a function of the unknown parameter vector $\Theta$ :

$$
\ell(K)=-\frac{1}{2} \sum_{t=1}^{T} \log \left|Q_{t}\right|-\frac{1}{2} \sum_{t=1}^{T}\left(B R_{t}-f_{t}\right)^{T} Q_{t}^{-1}\left(B R_{t}-f_{t}\right),
$$

where $f_{t}$ and $Q_{t}$ both depend implicitly on the vector $\Theta$. The previous expression can be numerically maximized in order to obtain the maximum likelihood estimator of the unknown parameters' vector $\Theta$;

$$
\Theta=\underset{\Theta}{\arg \max } \log \ell(\Theta) \text {. }
$$

Moreover, denoting by $H$ the Hessian matrix of $-\ell(\Theta)$, the inverse $H^{-1}$ provides an estimate of the variance of the estimator. Once the parameters $k_{t}$ and $\beta_{t}$ have been estimated, together with their errors $\omega_{k, t}, \omega_{\beta, t}$, future values for $k$ and $\beta$ can be calculated. Nite that the difference in the estimation between dynamic models and seemingly unrelated dynamic regressions stands in $\mathcal{D}_{t-1}$ : while in the first case it includes identity matrices for $V$ and $W$, in the second one it includes the estimated variances for $B R_{t}$ (in $V$ ) and for the parameters $k_{t}$ and $\beta_{t}$ (in $W$ ) obtained with the first step.

We remark that similar estimation procedure can be applied to parameter estimation of the second stage of the hierarchical process (multiple dynamic models).

In order to predict future values of the parameters in the state vector $\Theta_{t}^{i}$, we can extract $\omega_{k}^{i}$ and $\omega_{\beta}^{i}$ from their distributions (obtained on past data) for the next twelve months of the year to be predicted $\left(\hat{\omega}_{k, q}^{i}, \hat{\omega}_{\beta, q}^{i} ; q=1, \ldots, 12\right.$, $i=1, \ldots, N)$, thus estimating the parameters as follows:

$$
\left\{\begin{array}{l}
\hat{k}_{q}^{i}=\hat{k}_{q-1}^{i}+\hat{\omega}_{k, q}^{i} \\
\hat{\beta}_{q}^{i}=\hat{\beta}_{q-1}^{i}+\hat{\omega}_{\beta, q}^{i}
\end{array}\right.
$$

Future values for the parameters included in $\Gamma_{t}^{i}$ can be estimated through the same procedure.

Finally, in order to predict bank rates, we need to estimate reasonable future values of monetary rates. Consistently with the literature, we assume that their variations follow a Wiener process. 
More formally, assume that we want to predict the level of monetary rates for each of the next 12 months. Let $\widehat{\Delta M R}_{q}$ indicates the variation of the monetary rate in a given month. We then assume that all the $\widehat{\Delta M R}_{q}$ are independently and identically distributed Gaussian random variables, so that:

$$
\left\{\begin{array}{l}
\widehat{\Delta M R} \sim N\left(0, \sigma^{2}\right) \\
\widehat{M R}_{q}=\widehat{M R}_{q-1}+\widehat{\Delta M R}_{q} \quad \mathrm{q}=1, \ldots, 12 .
\end{array}\right.
$$

Equation (2.13) describes a recursive procedure to obtain predictions of the monetary rates for a given year ahead, based on the Wiener process assumption. We can then insert the predicted monetary rates as regressor values in the models of the previous Subsection and, thus, obtain predictions for the administered bank rates. Bank rates are thus predicted as:

$$
\widehat{B R}_{q}^{i}=\hat{k}_{q}^{i}+\hat{\beta}_{q}^{i} \widehat{M R}_{q} .
$$

The estimation of the state vector $\Theta_{t}^{i}$, based on the second stage of the hierarchical process in (2.7), can be achieved by similarly applying equation (2.12) for estimating $\hat{\Gamma}_{t}^{i}$, and thus deriving future values for $\Theta_{q}^{i}$ as follows:

$$
\widehat{\Theta}_{q}^{i}=\hat{\alpha}_{q}^{i}+\sum_{z=1}^{p} \hat{\gamma}_{q, z}^{i} \widehat{X}_{q, z}^{h}
$$

where as $\widehat{X}_{q, z}^{h}$ we will consider the forecasts of that economic variable made by official institutions (such as the European Central Bank and the International Monetary Fund).

It is important to test whether the addition of the hierarchical two-stages model improves the one-stage model. In order to compare them on the same playing field, we will run two kinds of test: an in-sample test, based on the MANOVA Wilk's $\Lambda$, and an out-of-sample test, based on Root Mean Square Errors $(R M S E)$ and on Mean Absolute Percentage Errors (MAPE). We use $M A P E$, together with $R M S E$, since it is less sensitive to occasional large errors and it allows for comparisons between different measure scales. 


\section{Data analysis and results}

\subsection{Descriptive analysis}

The recent financial crisis has had a major impact on the banking sector and, in particular, has led to a change in the relationship between monetary and administered rates. In the Eurozone, characterized by one monetary authority (the European Central Bank), that regulates still fragmented national markets, this effect is particularly evident: southern european countries, differently from what expected, have benefited very little from the drop of monetary rates that has followed the financial crisis.

To investigate the above issues we focus on seven european countries: France, Germany, Ireland, Italy, the Netherlands, Portugal and Spain.

Accordingly, we have collected from the ECB public database, monthly time series data on monetary rates and on aggregate bank administered rates on lendings, divided into three categories: (a) loans to non-financial corporates up to 1 Mln euros, shown in Figure 3.1; (b) loans to non-financial corporates over 1 Mln euros, shown in Figure 3.2: (c) loans to households for mortgages, shown in Figure 3.3. For the purposes of our analysis, the monetary rate used in this paper is the 3 -months Euribor. Note that such disaggregation of interest rates on loans to non-financial corporates can roughly be interpreted by saying that the first category represents loans to small-medium enterprises, and the second one represents loans to large corporates.

From Figure 3.1 interesting behaviours emerge: firstly, interest rates on loans in all countries, together with monetary rates, have strongly increased during the financial crisis of 2008, while dropping the following year. Secondly, the gap between such two rates has increased, since monetary rates are now very close to zero while interest rates on loans have remained quite high, even if they show a decreasing trend in 2014. Finally, interest rates on loans in core countries (France, Germany and the Netherlands) are very similar to each other, while the situation is more heterogenous in peripheral countries, with Portugal presenting the highest values during the entire period and Ireland being characterized by a strong volatility and an independent time-evolution after 2010.

Figure 3.2 reports interest rates on loans to non-financial corporates over $1 \mathrm{Mln}$ euros. Firstly, it is interesting to observe that, in absolute values, such interest rates are much lower than in the previous case, consistently with the assumption that loans to small-medium enterprises are riskier than loans 


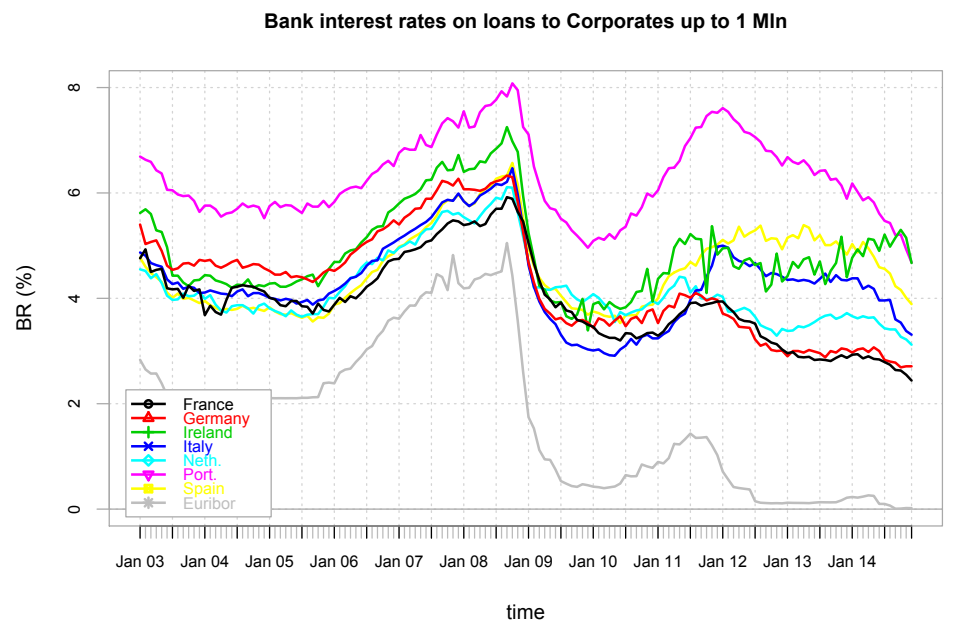

Figure 3.1: Interest rates on loans to non-financial corporates up to $1 \mathrm{Mln}$ euros and 3-months Euribor, from January 2003 until December 2014

to large corporates. Secondly, also this kind of interest rates has strongly increased during the financial crisis, decreasing in 2009. Finally, differently from before, all countries seem to have similar behaviours, strongly volatile in the short term but, on long run average, almost stable: again, Portugal presents a peculiar time-evolution, especially after 2010, characterized by very high and unstable values.

Figure 3.3 reports interest rates on loans to households for mortgages. As for loans to non-financial corporates over 1 Mln euros, this category of interest rates presents lower values with respect to loans to small-medium enterprises. However, the main peculiarity of this last rates consists in their completely heterogeneous behaviours after 2009: in the latest years, in fact, a common evolution pattern between different countries can not be detected, as well as, in each country, such time-evolutions are characterized by continuous changes. In particular, Italy, Portugal and Spain suffered an increase in interest rates during their sovereign crisis of 2012, while such increase is anticipated in Germany (2011) and hardly visible in France and the Netherlands; moreover, in France, Germany, Italy and the Netherlands interest rates on loans to households started decreasing in 2014, while such a trend can not be identified in the remaining countries.

From the above Figures it is clear that the relationship between bank rates 


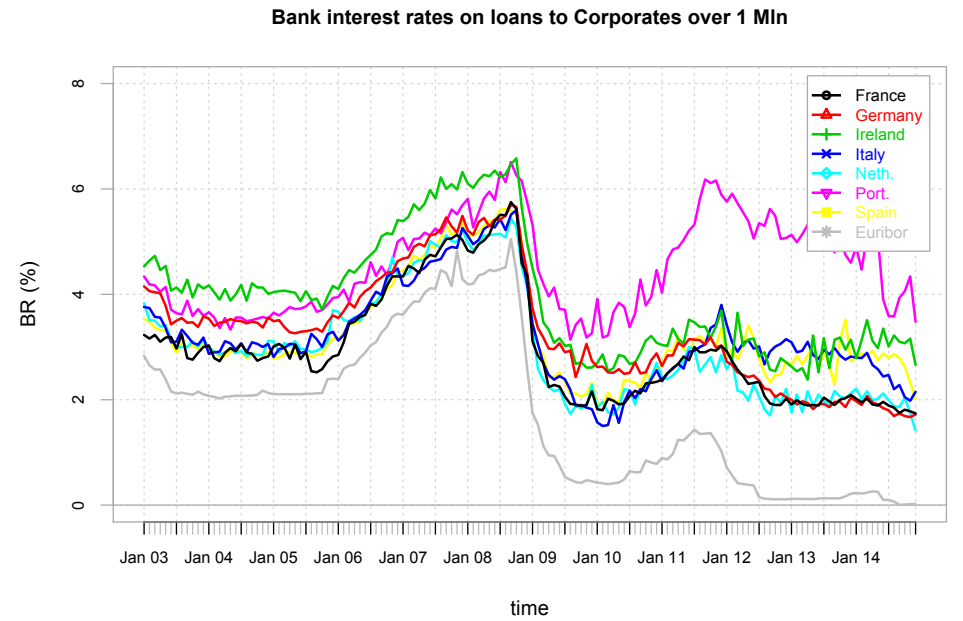

Figure 3.2: Interest rates on loans to non-financial corporates over $1 \mathrm{Mln}$ euros and 3-months Euribor, from January 2003 until December 2014

and monetary rates considerably changes over time for all types of lendings. Indeed, further analysis shows that, for small-medium corporate loans, the relationship is almost linear in all countries before the financial crisis of 2008; it remains so only in Germany and the Netherlands after the crisis. For large corporate loans, instead, core countries present a linear relationship during the entire period, while peripheral ones show a non-linear relation after the financial crisis. Family loans follow the pattern of small-medium corporate loans, with the Netherlands behaving as France and peripheral countries.

In order to better understand how interest rates on different kinds of loans and in different countries are correlated to each other and with 3-months Euribor, Table 3.1 reports correlation coefficients between them. In Table 3.1 corp 1 refers to interest rates on loans to non-financial corporates up to 1 Mln euros, corp2 refers to interest rates on loans to non-financial corporates over 1 Mln euros and fam refers to interest rates on loans to households for mortgages. 


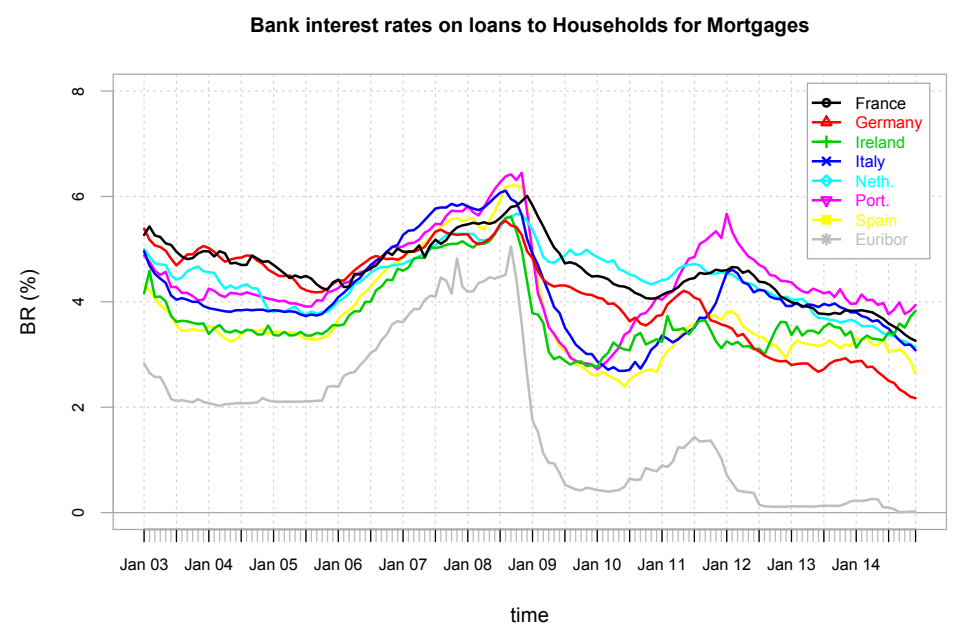

Figure 3.3: Interest rates on loans to households for mortgages and 3-months Euribor, from January 2003 until December 2014 


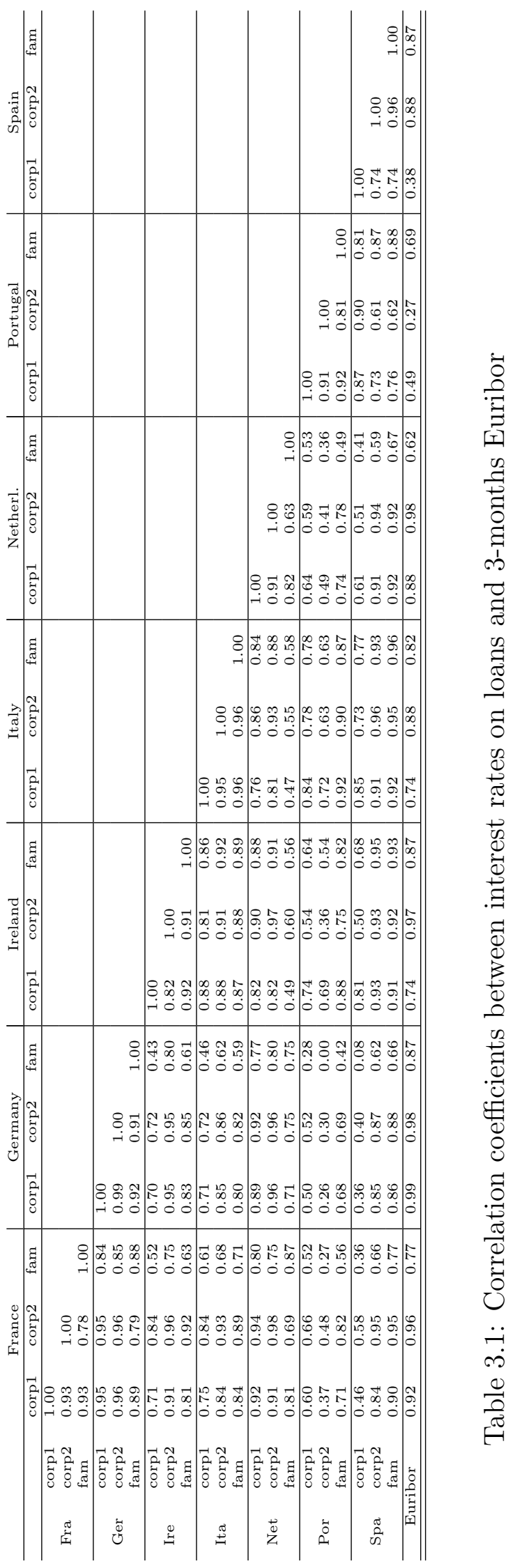


Table 3.1 shows interesting results. Firstly, by looking at the diagonal blocks, one can notice that, within each country, correlations between different kinds of loans are all positive and very high, meaning that a seemingly unrelated dynamic model has to be preferred with respect to a simple dynamic model in which different lending type rates are considered independently from each other. Secondly, by looking at the cross correlations between different countries, such relationships remain positive but lower: this suggests that, to avoid further complexity, lending rates of different countries can be assumed to be independent. Finally, by looking at the correlations between interest rates on loans and the 3-months Euribor, one can conclude that all interest rates on loans are positively and strongly related to monetary rates: again, Portugal and corp1 in Spain represent the only two exceptions, being characterized by very low correlations.

\subsection{Seemingly Unrelated Dynamic Regression}

For the model proposed in Section 2.2.1, we now show the corresponding estimation of the regression coefficients. As previously described, we first compute the dynamic model, deriving the coefficients $\hat{k}_{t}^{i}$ and $\hat{\beta}_{t}^{i}$ obtained considering each regression model independently from the others, for each $i \in V \times W$. After that we calculate, for each country, the variance-covariance matrices between such coefficients, obtained for the three kinds of loans: $W_{k}^{h}=\operatorname{Var}\left(\hat{k}^{1, h}, \hat{k}^{2, h}, \hat{k}^{3, h}\right)$ and $W_{\beta}^{h}=\operatorname{Var}\left(\hat{\beta}^{1, h}, \hat{\beta}^{2, h}, \hat{\beta}^{3, h}\right)$, for $h \in V$ and $\{1,2,3\} \in W$. These results, together with the variance-covariance matrix of the dependent variable $B R_{t}^{h}, V^{h}=\operatorname{Var}\left(B R^{1, h}, B R^{2, h}, B R^{3, h}\right)$, are used to derive the regression coefficients of the seemingly unrelated dynamic model described in (2.6).

The time-evolutions of the two estimated regression coefficients are presented in Figures 3.4, 3.5 and 3.6. More precisely, Figure 3.4 refers to interest rates on loans to non-financial corporates up to 1 Mln euros, Figure 3.5 refers to interest rates on loans to non-financial corporates over 1 Mln euros, Figure 3.6 refers to interest rates on loans to households for mortgages.

Figure 3.4 shows on the left the evolution of the intercepts $k_{t}^{h}$ and, on the right, the evolution of the coefficients $\beta_{t}^{h}$, which explain the time-varying elasticity of the monetary rates in the explanation of bank interest rates on loans to non-financial corporates up to $1 \mathrm{Mln}$ euros. From the analysis of the curves, important conclusions emerge. First, the contribution of monetary rates in the determination of bank rates has remained almost constant in all 

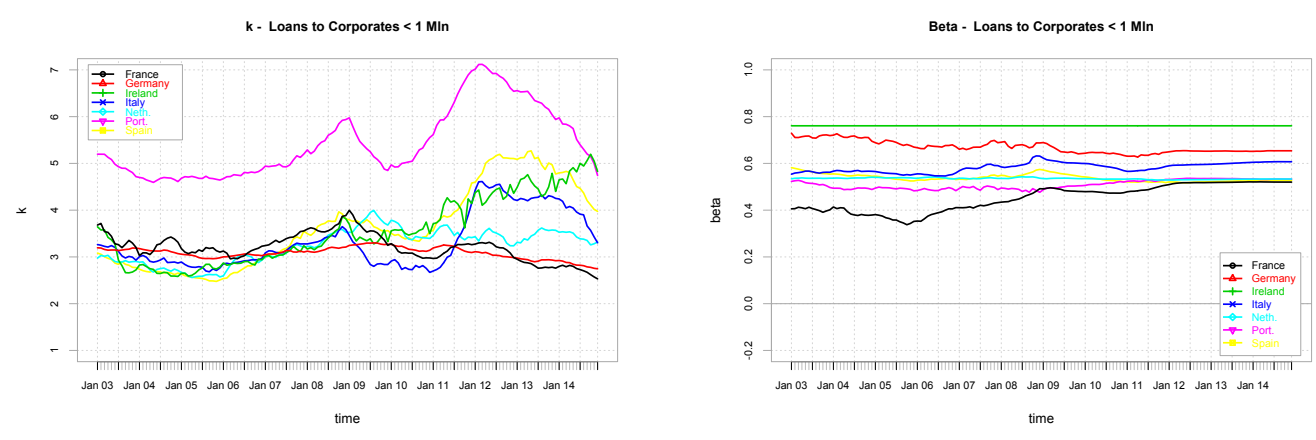

Figure 3.4: Regression coefficients obtained through the seemingly unrelated dynamic model for interest rates on loans to non-financial corporates up to 1 Mln euros, from January 2003 until December 2014

countries, with a weak peak at the end of 2008, coinciding with the financial crisis and the strong increase in 3-months Euribor. If one considers that, in the recent years, monetary rates are very close to zero, this result tells us that, in absolute value, bank rates are no more explained by monetary ones. Second, all the intercepts, which represent what monetary rates are not able to explain in the variability of bank rates, are strongly time-varying and heterogenous across different countries. In particular, before the crisis all the coefficients $k_{t}^{h}$ move together, but the situation changes after 2009: in the last period, in fact, it is clear that France, Germany and the Netherlands (core countries) on one side, as well as Italy and Spain on the other, behave quite similarly; Portugal is characterized by the highest values during the whole period; Ireland follows a completely different trend.

Figure 3.5 shows on the left the evolution of the intercepts $k_{t}^{h}$ and, on the right, the evolution of the coefficients $\beta_{t}^{h}$, referred to bank interest rates on loans to non-financial corporates over $1 \mathrm{Mln}$ euros. From the analysis of these results an important difference with respect to the previous case can be detected: in all countries, the contribution of monetary rates in the determination of bank rates on loans to large corporates is much higher than the one referred to interest rates on loans to small-medium enterprises, as the residual component, expressed by $k_{t}^{h}$, is much lower. Moreover, the time evolution of $\beta_{t}^{h}$ is constant in almost all countries, with the exception of France and, to a lesser extent, of Italy. In addition, a common pattern between the time evolution of the intercepts $k_{t}^{h}$ can not be identified after 

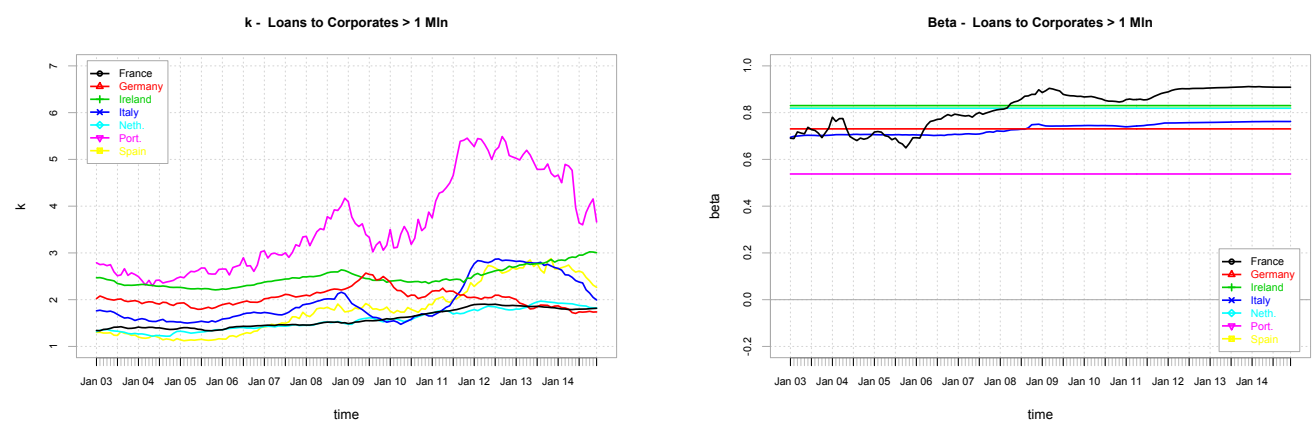

Figure 3.5: Regression coefficients obtained through the seemingly unrelated dynamic model for interest rates on loans to non-financial corporates over 1 Mln euros, from January 2003 until December 2014

2009, neither for core nor peripheral countries.
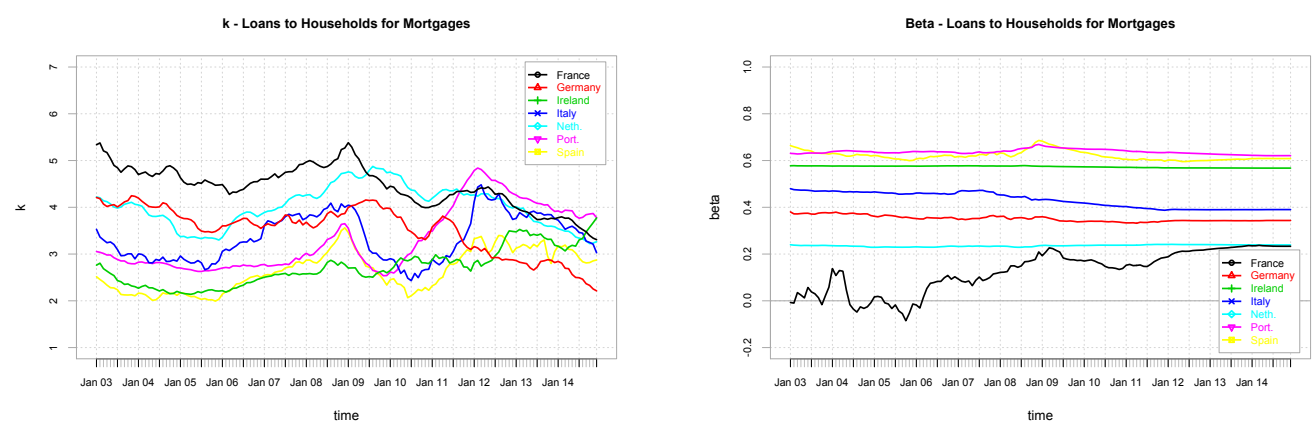

Figure 3.6: Regression coefficients obtained through the seemingly unrelated dynamic model for interest rates on loans to households for mortgages, from January 2003 until December 2014

Figure 3.6 shows on the left the evolution of the intercepts $k_{t}^{h}$ and, on the right, the evolution of the coefficients $\beta_{t}^{h}$, referred to bank interest rates on loans to households for mortgages. Similarly to the previous two kinds of loans, the coefficients $\beta_{t}^{h}$ look almost constant in all countries and during the whole period, with the exception of France. By looking at the coefficients $k_{t}^{h}$, the situation is extremely heterogeneous across different countries, both before and after the financial crisis.

To summarize, from the seemingly unrelated dynamic model, proposed 
in (2.6) and analyzed in this Section, the most important conclusions are as follows. (a) The contribution of monetary rates in the composition of bank rates is almost constant in time, in all countries and for the three kinds of loans, with the exception of France. (b) Interest rates on loans to large corporates are much more explained by monetary rates with respect to the other two kinds of loans, because of their higher values for $\beta_{t}^{h}$ and of their lower values for $k_{t}^{h}$. (c) The time evolution of the intercepts $k_{t}^{h}$ is extremely heterogenous, especially after 2009 and for interest rates on loans to households: this means that country-specific effects have to be considered in the explanation of bank rates. (d) For small-medium enterprises, we observe a divergence effect between core and peripheral countries, in the behaviour of $k_{t}^{h}$ after the crisis.

\subsection{Hierarchical Dynamic Models}

In this Subsection we apply the hierarchical procedure proposed in (2.7) to the intercept coefficients $k_{t}^{h}$ previously obtained through the seemingly unrelated dynamic model, to take into account country-specific macroeconomic effects in the explanation of the time-varying parameters.

We propose the following three regressors: interest rates on 10-years government bonds, aggregate interest rates on deposits and annual variations of GDP. This choice is due to both practical and economical motivations. Firstly, they all are publicly available data, so this analysis can be replicated. Secondly, interest rates on government bonds can be considered as a proxy for sovereign risk; interest rates on deposits, together with interest rates on loans, define the income of the banking sector in each country; annual variations of GDP describe, at the country level, the overall risk of the corporate sector. Consistently with interest rates on loans, all the variables described so far have monthly frequencies and have been collected from the ECB database, from January 2003 until December 2014. We remark that GDP variations are quarterly published, so we have applied linear interpolation to obtain monthly data.

In order to better understand how these explanatory regressors have evolved in time, Figure 3.7 shows interest rates on 10-years government bonds, Figure 3.7 shows aggregate interest rates on deposits, and Figure 3.7 shows annual GDP growth rates, in the seven considered european countries.

Figure 3.7 shows a great differentiation between european countries after the financial crisis of 2008. In the first period, in fact, interest rates on 


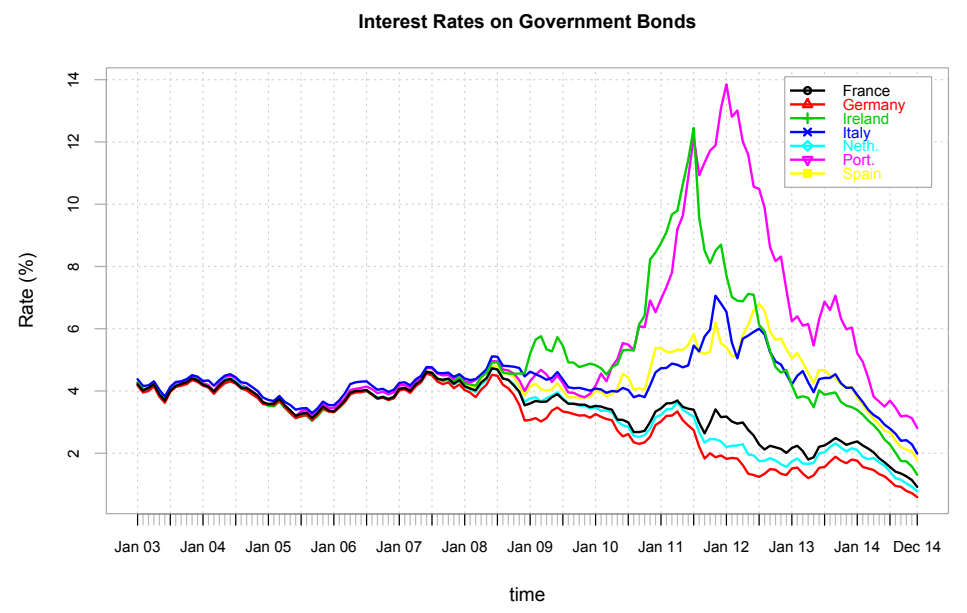

Figure 3.7: Interest rates on 10-years government bonds, from January 2003 until December 2014

government bonds are extremely similar to each other, following the same dynamics. After 2008 the situation completely changes: on one hand, core countries are clearly characterized by similar values and by a long-run average decreasing trend; on the other hand, rates on government bonds in peripheral countries diverge, with Ireland and Portugal presenting the highest peaks during their sovereign crisis (respectively in 2011 and 2012).

Figure 3.8 shows a more heterogeneous behaviour with respect to Figure 3.7. Interest rates on deposits strongly increased in 2008 in all countries and decreased afterwards, together with the drop of monetary rates. In the recent years, such rates increased again during the sovereign crisis of 2012, starting a further decrease in 2013. It is important to observe the peculiar case of France, whose bank rates on deposits have not been subject to great changes during the entire period, remaining, on average, almost constant.

Figure 3.9 represents the economic growth evolutions of the seven european countries and shows many similarities across them. All GDP growth rates, in fact, dropped during both the financial crisis and the sovereign crisis: among them, Germany and France suffered less the sovereign crisis of 2012, while the situation is reversed for Italy, Portugal and Spain. Finally, it is interesting to observe the strong GDP growth in Ireland, started in 2013 after the important package of reforms introduced by the Irish government 


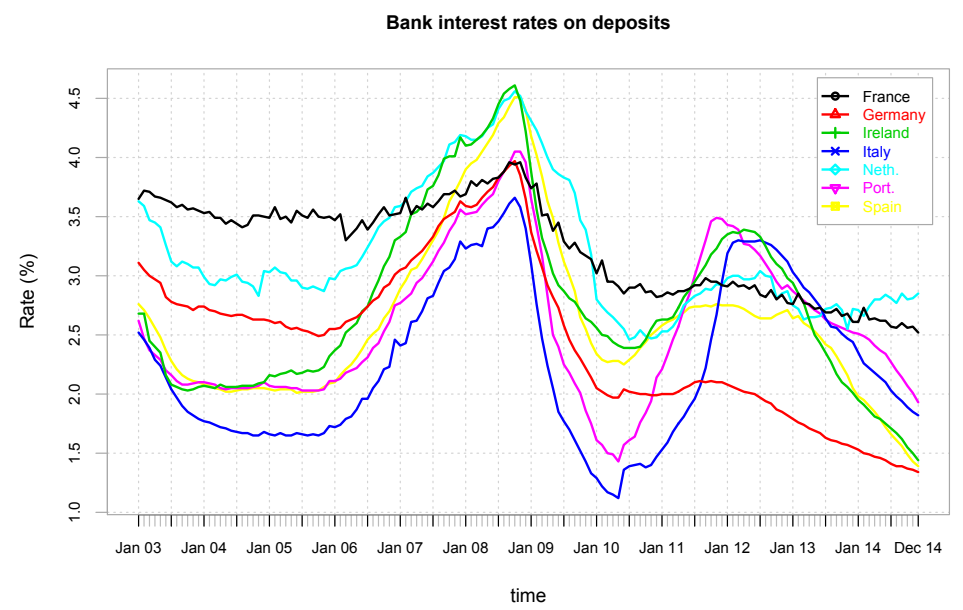

Figure 3.8: Aggregate interest rates on deposits, from January 2003 until December 2014

in order to recover from their dramatic crisis.

In order to understand how the exogenous variables previously described are related to each other, to interest rates on loans and to monetary rates, Table 3.2 shows the correlation coefficients for all the countries.

\begin{tabular}{lllll} 
& & Bond & Deposit & $\Delta$ GDP \\
\hline \multirow{2}{*}{ Fra } & loans corp1 & 0.824 & 0.893 & -0.228 \\
& loans corp2 & 0.716 & 0.771 & -0.146 \\
& loans fam & 0.833 & 0.891 & -0.306 \\
\hline \multirow{2}{*}{ Ger } & loans corp1 & 0.854 & 0.947 & -0.159 \\
& loans corp2 & 0.833 & 0.952 & -0.173 \\
& loans fam & 0.965 & 0.926 & -0.160 \\
\hline \multirow{2}{*}{ Ire } & loans corp1 & -0.068 & 0.694 & -0.300 \\
& loans corp2 & -0.185 & 0.615 & -0.169 \\
& loans fam & -0.158 & 0.682 & -0.261 \\
\hline \multirow{2}{*}{ Ita } & loans corp1 & 0.357 & 0.836 & -0.404 \\
& loans corp2 & 0.296 & 0.685 & -0.263 \\
& loans fam & 0.310 & 0.763 & -0.366 \\
\hline \multirow{2}{*}{ Net } & loans corp1 & 0.705 & 0.853 & 0.088 \\
& loans corp2 & 0.714 & 0.743 & 0.339 \\
& loans fam & 0.710 & 0.757 & -0.216 \\
\hline \multirow{2}{*}{ Por } & loans corp1 & 0.494 & 0.935 & -0.567 \\
& loans corp2 & 0.544 & 0.908 & -0.584 \\
& loans fam & 0.254 & 0.857 & -0.314 \\
\hline \multirow{2}{*}{ Spa } & loans corp1 & 0.394 & 0.719 & -0.410 \\
& loans corp2 & 0.075 & 0.699 & 0.090 \\
& loans fam & 0.075 & 0.778 & 0.013 \\
\hline \hline
\end{tabular}

Table 3.2: Correlation coefficients between country-specific regressors and interest rates on loans

Table 3.2 concentrates on correlations between interest rates on loans and 


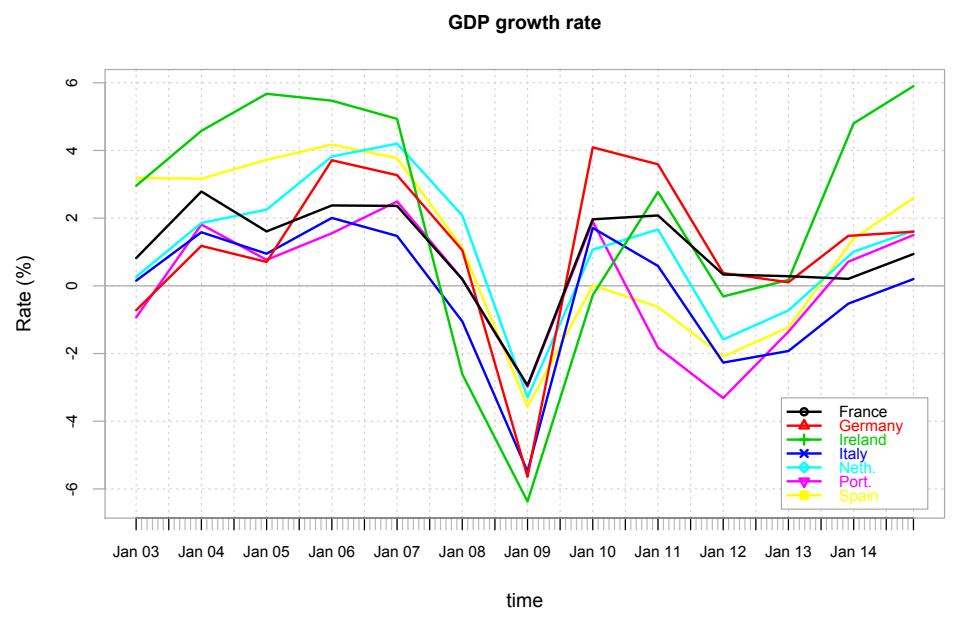

Figure 3.9: Annual GDP growth rates, from January 2003 until December 2014

exogenous country-specific variables, showing interesting results. Firstly, one can notice that there is a clear difference between core and peripheral countries. France, Germany and the Netherlands are characterized by high and positive coefficients between rates on government bonds and interest rates on loans: this is consistent with the fact that, if bond rates increase, sovereign risks increase and, consequently, loan rates increase. Such correlations, however, are very low or negative in Ireland, Italy, Portugal and Spain. Secondly, the GDP growth rate is negatively related to interest rates on loans in all countries, consistently with the fact that when the economy improves, the demand for loans increases and, consequently, interest rates on loans decrease.

After having described the variables involved in the second step of the hierarchical model, we now show the corresponding estimation of the regression coefficients for the model proposed in (2.7), with

$$
F_{\theta, t}^{h}=\left[\begin{array}{c}
1 \\
X_{1, t}^{h} \\
\vdots \\
X_{p, t}^{h}
\end{array}\right]=\left[\begin{array}{c}
1 \\
\text { Bond }_{t}^{h} \\
\text { Deposit } \\
\Delta G D P_{t}^{h}
\end{array}\right], \quad \Gamma_{t}^{j, h}=\left[\begin{array}{c}
\alpha^{j, h} \\
\gamma_{1, t}^{j, h} \\
\gamma_{2, t}^{j, h} \\
\gamma_{3, h}^{j, h} \\
\gamma_{4, t}^{j, h}
\end{array}\right],
$$

and where $\Theta_{t}^{h}$, the dependent variable, is the vector of the regression 
coefficients derived in Section 3.2. We remark that, since the coefficients $\beta_{t}^{h}$ previously obtained are almost constant, this second step of the hierarchical procedure will be applied only to the intercepts $k_{t}^{h}$, so that $\Theta_{t}^{h}$ becomes $\Theta_{t}^{h}=\left(k_{t}^{1, h}, k_{t}^{2, h}, k_{t}^{3, h}\right)$, with $h \in V$ and $\{1,2,3\} \in W$.

The time-evolutions of the four regression coefficients are presented in Figures 3.10, 3.11 and 3.12. More precisely, Figure 3.10 refers to interest rates on loans to non-financial corporates up to $1 \mathrm{Mln}$ euros, Figure 3.11 refers to interest rates on loans to non-financial corporates over 1 Mln euros, Figure 3.12 refers to interest rates on loans to households for mortgages. We remark that, in each Figure, only significant regressors have been plotted: this implies, for example, that Germany does not appear in the following graphs since its $\Theta_{t}^{g e r}$ does not significantly depend on exogenous variables.

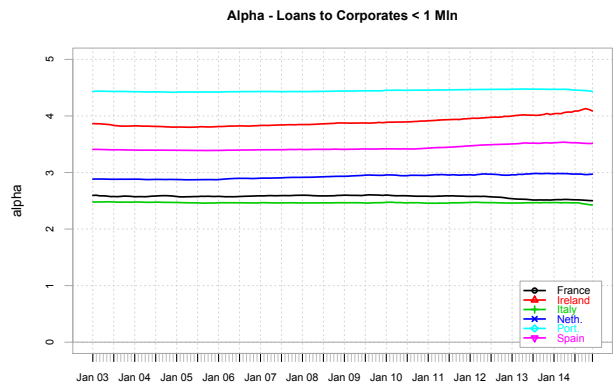

time

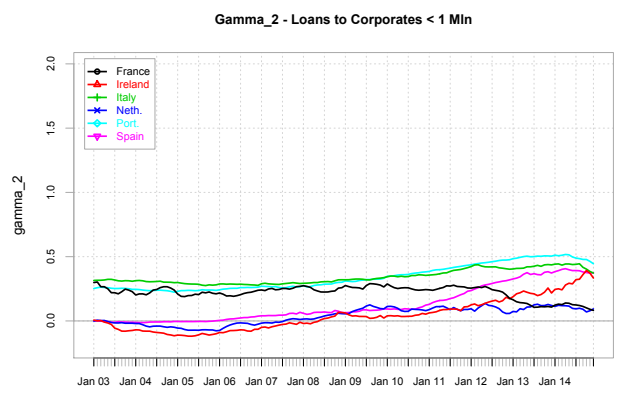

time

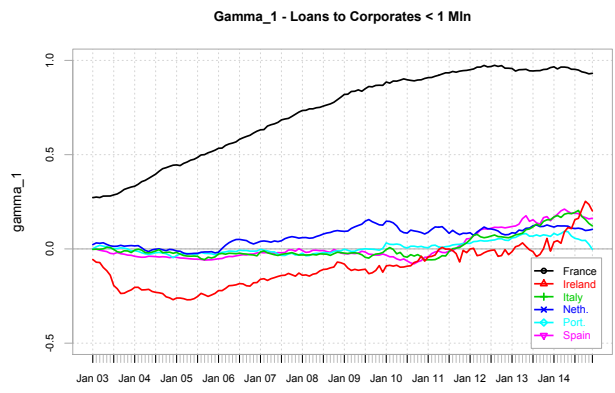

time

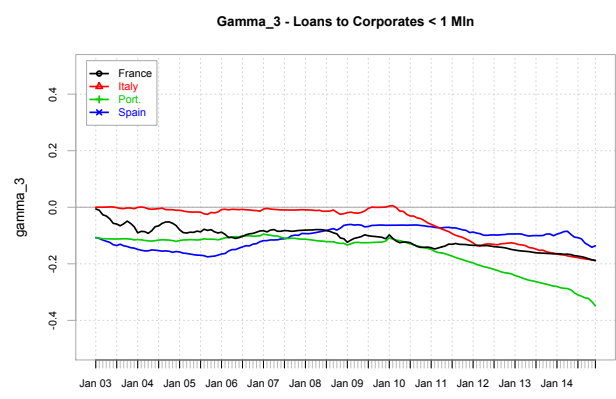

time

Figure 3.10: Regression coefficients obtained through the multiple dynamic model for $\Theta_{t}^{j, h}$ to non-financial corporates up to 1 Mln euros, from January 2003 until December 2014

Figure 3.10 shows the time dynamics of the four components of $\Gamma_{t}^{j, h}$, thus representing how these components are important in describing the time evo- 
lution of bank rates on loans that has not been fully captured by monetary rates. Firstly, one can notice that the coefficients $\alpha$ are now almost constant, meaning that they can be interpreted as the fixed, long-run average components of bank rates, not explained by other exogenous variables. Secondly, interest rates on government bonds seem to have a significant effect only in France, Ireland and the Netherlands during the entire period, and in all countries after 2012. The contribution of interest rates on deposits is particularly significant in Italy and Spain during the whole years, while, since 2012, it started decreasing in France and increasing in Ireland and Spain. Finally, the contribution of the GDP growth rate became more significant after the financial crisis of 2008, not only for peripheral countries but also for France.

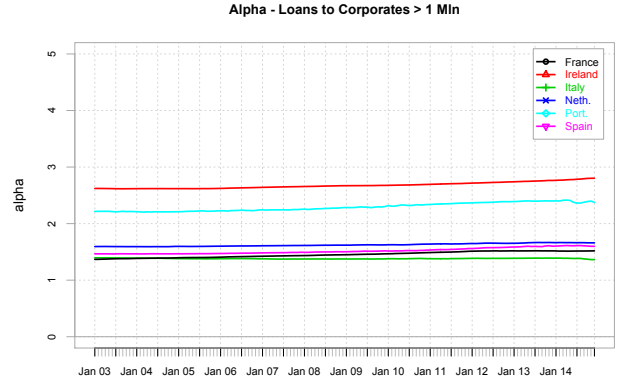

time

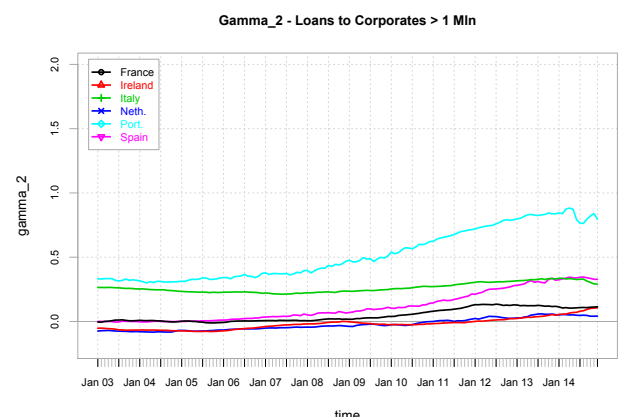

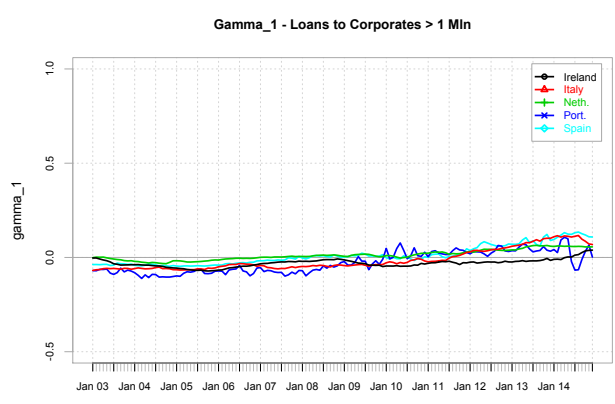

time

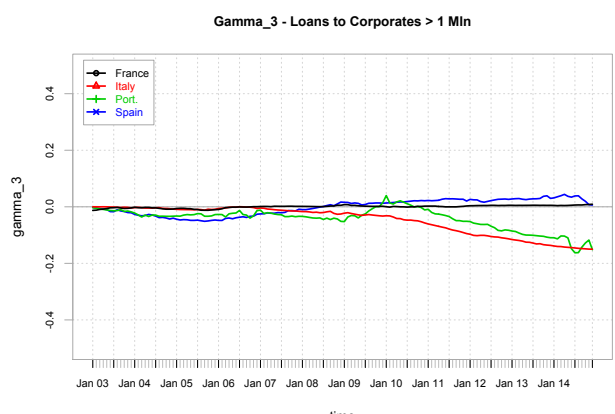

Figure 3.11: Regression coefficients obtained through the multiple dynamic model for $\Theta_{t}^{j, h}$ to non-financial corporates over 1 Mln euros, from January 2003 until December 2014

Figure 3.11 shows the time dynamics of the components of $\Gamma_{t}^{j, h}$ for loans to non-financial corporates over 1 Mln euros. By looking at the residual parts $\alpha_{t}$, two conclusions emerge: firstly, in all countries the estimated coefficients are 
almost constant; secondly, they are significantly lower than the ones obtained in the previous case. This is a further confirm of the fact that interest rates on loans to large corporates are much more explained by monetary rates, as well as they have a lower long-run average value since this kind of lending activity is riskier. As in the previous case, the contribution due to interest rates on deposits is very high in peripheral countries, especially in Portugal, meaning that, in such economies, banks adjust interest rates on loans to large corporates (assets) according to the ones on deposits (liabilities), or vice-versa, thus equilibrating their interest margins. The contribution of the GDP growth rates is almost zero in France and Spain, while it is strongly decreasing in Italy and Portugal.

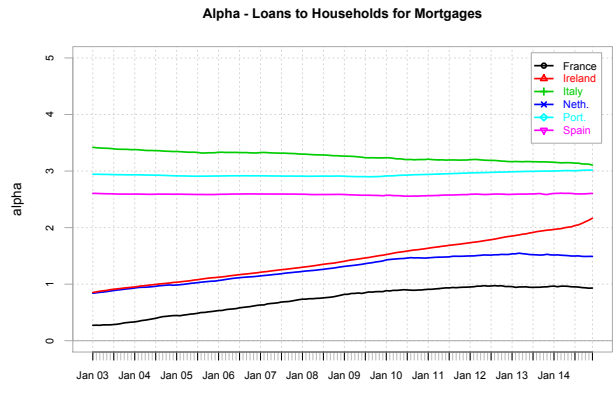

time

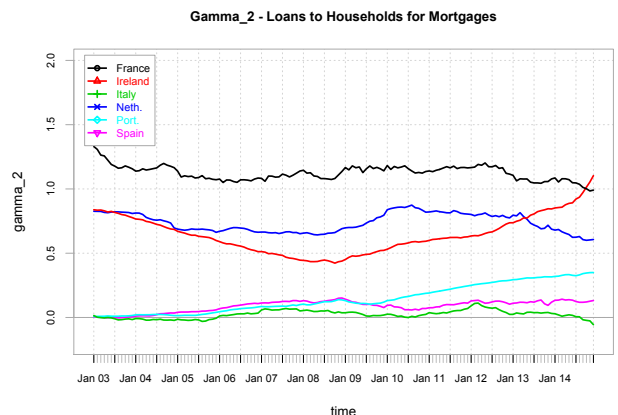

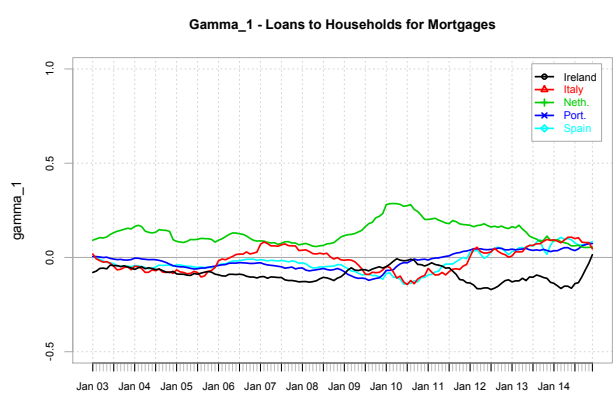

time

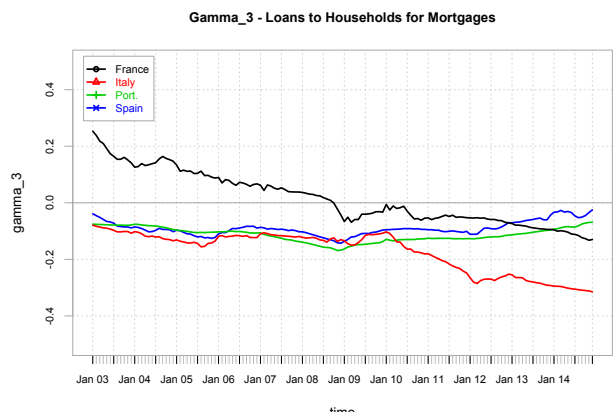

Figure 3.12: Regression coefficients obtained through the multiple dynamic model for $\Theta_{t}^{j, h}$ to households for mortgages, from January 2003 until December 2014

Figure 3.12 shows the time dynamics of the components of $\Gamma_{t}^{j, h}$ for loans to households for mortgages. Differently from loans to corporates, in this case the residual components $\alpha_{t}$ are constant only in Portugal and Spain: they 
show a weak decreasing evolution in Italy, and a strong increase in France, Ireland and the Netherlands, meaning that, in these countries, a further level of explanation should be investigated. The contribution of interest rates on government bond is significant in all countries with the exception of France, even if shows very heterogenous behaviors, not only across different geographical areas but also across time. The most interesting result regards the contribution of interest rates on deposits: $\gamma_{2}$, in fact, presents high values and similar evolutions in France and the Netherlands, while in Ireland it started increasing after the financial crisis, showing an even faster increase after the reform of the banking system of 2013. Italy, Portugal and Spain, on the other hand, are characterized by low values. Finally, the contribution of GDP growth rates shows two distinct patterns: on one side, France and Italy are characterized by a monotonic decreasing trend, while Portugal and Spain have similar, more stable behaviours.

As previously observed, France presents a peculiar situation since its coefficients $\beta_{t}$, derived with the first seemingly unrelated dynamic model, are time-varying for loans to big firms and households. By computing the multiple dynamic regression described in this Section also on such two coefficients, the results show that these stickiness parameters, which explain the contribution of monetary rates in the transmission mechanism to bank rates, significantly and negatively depends on interest rates on deposits.

To summarize, from the dynamic hierarchical model proposed in (2.7) and analyzed in this Section, the most important conclusions are as follows. Germany lending interest rates depend only on monetary rates, and this is consistent with its role as the pivotal country of the Euro Area. The behavior of the Netherlands is similar to that of Germany for the corporate sectors but, for households, there is an additional effect of sovereign bond rates and of bank deposit rates, which are the result of the bank search for a profit margin. The behavior of France is mixed between core and peripheral countries. On one hand, large corporate rates are affected only by monetary rates, as in Germany and the Netherlands. On the other hand, household rates are affected by deposit rates and GDP variations, as it occurs in peripheral countries. Furthermore, small corporate rates are affected by sovereign bond rates, deposit rates and GDP variations, as in peripheral countries. Italy, Portugal and Spain, besides the previously mentioned ones, also show a dependence of large corporate rates on deposit rates and GDP variations. This is consistent with the bank search for a profit margin and with the pricing that affects corporate risk. Last, the behavior of Ireland is 
close to that of peripheral countries in the pre-crisis period, and to that of core countries in the latest years.

\subsection{Model Adequacy}

After having estimated the coefficients of the seemingly unrelated dynamic model and of the multiple dynamic regression, we are able to predict monthly administered bank interest rates for 2014. In order to compute such predictions, we firstly estimate the parameters of the two dynamic models according to (2.12); secondly, we use a range of monetary rates scenarios, simulated from a Wiener process as described in (2.13), in order to obtain future values for monetary rates; thirdly, for the regressors that appear in the multiple dynamic model, we calculate an average of the official forecasting measures made by financial institutions (ECB and IMF).

Figure 3.13 reports the predicted interest rates on loans, in the different countries, made by using the hierarchical model (2.7).

From Figure 3.13 one can firstly notice that the hierarchical dynamic procedure proposed in this work predicts quite well future values of interest rates on loans, in almost all countries. France, Germany, the Netherlands and Spain are the ones with the highest predictive performance for the three kinds of loans. Ireland presents some problems in the case of loans to households. This is due to the fact that, as shown in Figure 3.12, the intercept $\alpha$ of the multiple regression model has started strongly increasing in 2013 (after the bank reforms approved by the government). In Portugal the same problem regards loans to small-medium enterprises, because of the strong and unpredictable decreasing contribution of interest rates on bonds and interest rates on deposits in 2014, and loans to large corporates, because of the strong increase contribution of interest rates on deposits in the last year.

In order to test whether the hierarchical model has improved the explanation of bank interest rates on loans with the one-stage model, we have performed two kinds of tests, as described in Section 2.3: an in-sample test (Wilk's $\Lambda$ test) and an out of sample test (RMSE and MAPE measures).

Table 3.3 reports the coefficients $\Lambda$ referred, respectively, to the nonhierarchical process $\left(\lambda_{1}\right)$ and to the results obtained with the complete hierarchical model $\left(\lambda_{2}\right)$.

Table 3.3 clearly shows that the hierarchical model strongly increases the performance of the overall model, dropping its unexplained variance. Note that Portugal and Ireland are characterized by the highest values, thus 

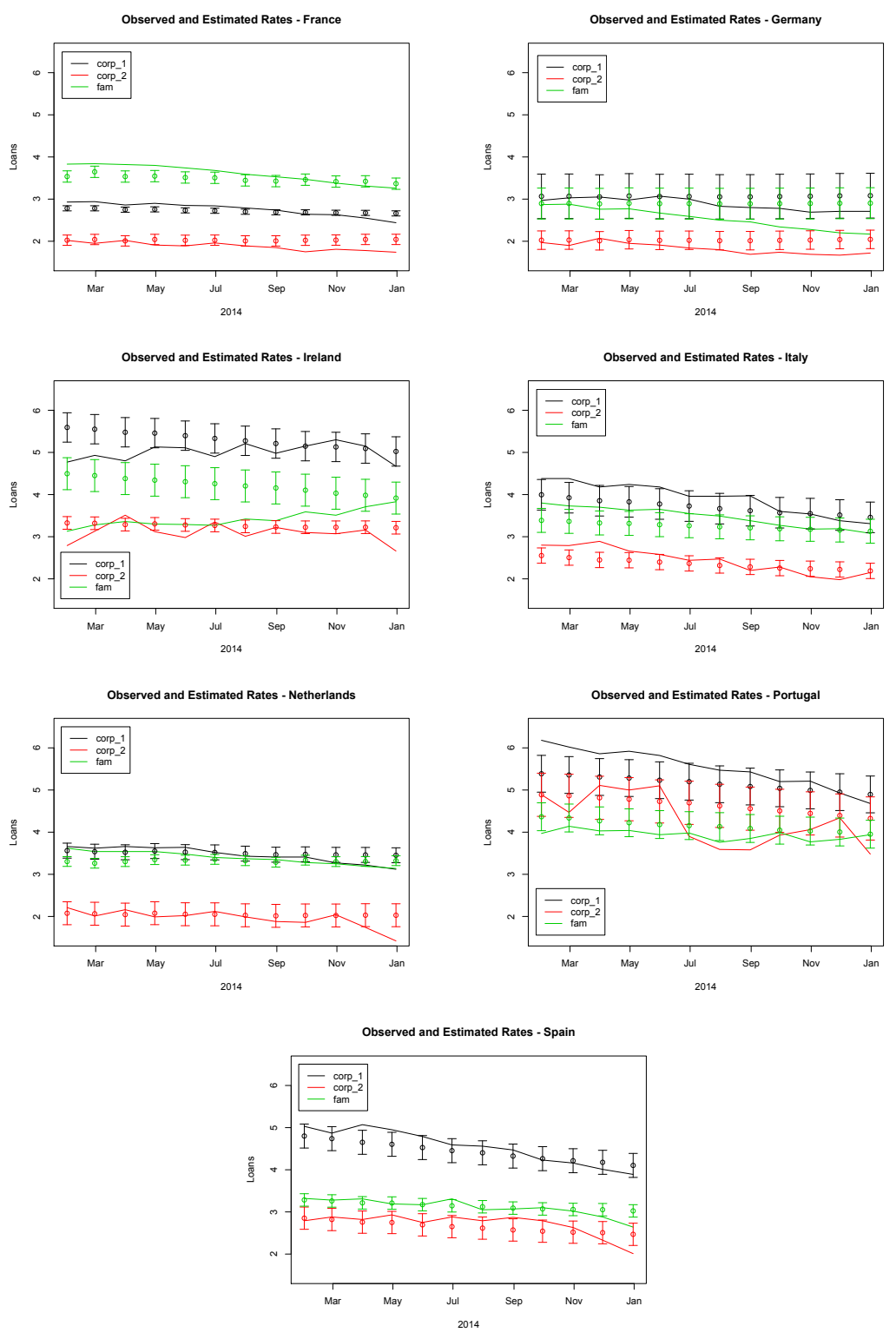

Figure 3.13: Observed and estimated interest rates on loans, from January 2003 until December 2014

confirming our previous results.

Table 3.4 reports the measures $R M S E$ and $M A P E$ referred, respectively, 


\begin{tabular}{llllllll}
$\Lambda$ & France & Germany & Ireland & Italy & Netherlands & Portugal & Spain \\
\hline$\lambda_{1}$ & 0.010 & 0.002 & 0.117 & 0.087 & 0.014 & 0.200 & 0.018 \\
$\lambda_{2}$ & $9.58 \cdot 10^{-9}$ & & $8.62 \cdot 10^{-7}$ & $2.02 \cdot 10^{-8}$ & $3.53 \cdot 10^{-9}$ & $7.98 \cdot 10^{-7}$ & $5.85 \cdot 10^{-10}$ \\
\hline \hline
\end{tabular}

Table 3.3: $\Lambda$ Wilk's test, obtained by using only the first stage $\left(\lambda_{1}\right)$ or both the stages $\left(\lambda_{2}\right)$ of the hierarchical process

to the non-hierarchical model $\left(R M S E_{1}, M A P E_{1}\right)$ and to the complete hierarchical model $\left(R M S E_{2}, M A P E_{2}\right)$ : in addition, the percentage error reductions obtain through the addition of the second stage are reported $\left(\Delta_{R M S E} \%\right.$ and $\left.\triangle_{M A P E} \%\right)$.

\begin{tabular}{lllll|lll} 
Country & Loans & $R M S E_{1}$ & $R M S E_{2}$ & $\Delta_{R M S E} \%$ & $M A P E_{1}$ & $M A P E_{2}$ & $\Delta_{M A P E}$ \\
\hline \multirow{2}{*}{ Fra } & corp 1 & 0.0387 & 0.0155 & $-60.0 \%$ & 0.0873 & 0.0416 & $-52.4 \%$ \\
& corp 2 & 0.0552 & 0.0309 & $-43.9 \%$ & 0.1161 & 0.0813 & $-30.0 \%$ \\
& fam & 0.0835 & 0.0339 & $-59.4 \%$ & 0.0759 & 0.0437 & $-42.4 \%$ \\
\hline \multirow{2}{*}{ Ger } & corp 1 & 0.0529 & 0.0529 & $0.0 \%$ & 0.0655 & 0.0655 & $0.0 \%$ \\
& corp 2 & 0.0554 & 0.0554 & $0.0 \%$ & 0.1175 & 0.1175 & $0.0 \%$ \\
& fam & 0.1856 & 0.1856 & $0.0 \%$ & 0.1501 & 0.1501 & $0.0 \%$ \\
\hline \multirow{2}{*}{ Ire } & corp 1 & 0.2271 & 0.1761 & $-22.4 \%$ & 0.0860 & 0.0688 & $-20.0 \%$ \\
& corp 2 & 0.3417 & 0.0758 & $-77.8 \%$ & 0.1706 & 0.0751 & $-56.0 \%$ \\
& fam & 0.7018 & 0.0476 & $-93.2 \%$ & 0.2340 & 0.0659 & $-71.8 \%$ \\
\hline \multirow{2}{*}{ Ita } & corp 1 & 0.3495 & 0.0917 & $-73.8 \%$ & 0.1284 & 0.0651 & $-49.3 \%$ \\
& corp 2 & 0.2869 & 0.0459 & $-84.0 \%$ & 0.1916 & 0.0724 & $-62.2 \%$ \\
& fam & 0.1968 & 0.0719 & $-63.5 \%$ & 0.1134 & 0.0626 & $-44.8 \%$ \\
\hline \multirow{2}{*}{ Net } & corp 1 & 0.0832 & 0.0224 & $-73.0 \%$ & 0.0673 & 0.0360 & $-46.5 \%$ \\
& corp 2 & 0.0727 & 0.0458 & $-37.0 \%$ & 0.1117 & 0.0848 & $-24.1 \%$ \\
& fam & 0.0827 & 0.0293 & $-64.6 \%$ & 0.0745 & 0.0418 & $-43.8 \%$ \\
\hline \multirow{2}{*}{ Por } & corp 1 & 0.4774 & 0.2206 & $-53.8 \%$ & 0.1065 & 0.0719 & $-32.5 \%$ \\
& corp 2 & 0.5649 & 0.2589 & $-54.2 \%$ & 0.1657 & 0.1003 & $-39.4 \%$ \\
& fam & 0.0557 & 0.0251 & $-54.9 \%$ & 0.0554 & 0.0540 & $-2.5 \%$ \\
\hline \multirow{2}{*}{ Spa } & corp 1 & 0.2690 & 0.0480 & $-82.2 \%$ & 0.0953 & 0.0412 & $-56.8 \%$ \\
& corp 2 & 0.0901 & 0.0445 & $-50.6 \%$ & 0.0737 & 0.0690 & $-6.4 \%$ \\
& fam & 0.0454 & 0.0186 & $-58.9 \%$ & 0.0532 & 0.0301 & $-43.5 \%$ \\
\hline \hline
\end{tabular}

Table 3.4: RMSE, MAPE and the percentage improvement of the model, obtained by using only the first stage $\left(R M S E_{1}\right)$ or both the stages $\left(M A P E_{2}\right)$ of the hierarchical process

Table 3.4 provides a further confirmation of the performance improvement introduced in the methodological framework with the hierarchical model. Furthermore, by looking at the root mean square errors, it seems that France, the Netherlands and Spain are characterized by the lowest errors, consistently with Figure 3.13. However, by concentrating on percentage measures (MAPE), the situation changes, showing more homogeneous results, with both Italy and Portugal significantly affected by worse predictions. The greatest improvements in the model can be detected for loans to non-financial corporates up to 1 Mln euros in France and Spain, loans to households in Ireland and loans to non-financial corporates over 1 Mln euros in Italy. 
By comparing these results with Figure 3.10, we can conclude that, in France, the contribution of interest rates on government bonds in the explanation of bank rates on loans to small-medium enterprises is crucial. Similarly, in Spain the most important components for determining interest rates on loans to small-medium enterprises are interest rates on deposits and the GDP growth rate. By looking at Figure 3.11, in Ireland interest rates on loans to households are mostly dependent on interest rates on deposits, while in Italy the explanation of interest rates on loans to large corporates mostly rely on the GDP growth rate, especially after the financial crisis of 2009.

\section{Conclusions}

The paper has two main methodological contributions. Firstly, it introduces a dynamic model able to capture the evolving relationship between bank and monetary rates, taking into account correlations between different kinds of loans within each country. Secondly, it proposes a hierarchical model, to understand how country-specific macroeconomic factors may have different effects on the monetary transmission. Both models perform quite well from a predictive viewpoint.

The application of the methodology shows that the proposed models are able to explain the heterogenous transmission mechanism of monetary rates according to specific temporal and geographical contexts. Moreover, it shows that the financial crisis and the sovereign crisis have differently affected the time dynamics of bank interest rates on loans, with the former leading to homogenous reactions in all countries and the latter causing a clustering effect between peripheral and core countries.

The effect of monetary rates on bank rates is different according to different lending types: large corporate loans are the most affected, whereas small-medium corporate loans and household loans depend less on monetary rates and more on country-specific macroeconomic factors, such as interest rates on deposits and GDP variations. This dependency can be explained, respectively, as the consequence of the bank need for returns, mostly determined by interest spreads, and as the impact of corporate and family risk.

The dependence of bank rates on monetary rates considerably varies also across countries. In core countries, such as Germany and the Netherlands, bank rates depend almost exclusively on monetary rates and, therefore, the transmission of monetary policy is expected to be effective. In peripheral 
countries, instead, all lending rates depend on bank risk, corporate risk and, more recently, sovereign risk, as reflected by deposit rates, GDP variations and sovereign bond rates. Hence, in these countries, the transmission of the monetary policy appears to be more problematic.

Further research work should take into account correlations between countries, so to investigate how monetary policies can affect and prevent the transmission of systemic risk. Other geographical areas should also be considered to verify the validity of the model in a more general context. From a methodological viewpoint, parameter estimation could be performed by means of Bayesian methods, which will allow model uncertainty to be taken into account.

\section{Acknowledgements}

The Authors acknowledge financial support from the PRIN project MISURA: multivariate models for risk assessment, and of the $\mathrm{PhD}$ programme in Economics and management of the technology at the University of Pavia. The paper has been written by Laura Parisi, Phd student, with the supervision and editing of Professor Paolo Giudici.

\section{References}

Ballester, L., Ferrer, R., Gonzales, C., Soto, G.M., 2009. Determinants of interest rate exposure of the Spanish banking industry. Working Paper, University of Castilla-La Mancha.

Borio, C., Chu, H., 2012. Capital regulation, risk-taking and monetary policy: A missing link in the transmission mechanism? Journal of Financial Stability 8(4), 236-251.

Chong, B. S., Liu, M., Shrestha, K., 2006. Monetary transmission via the administered interest rates channel. Journal of Banking and Finance 30(5), 1467-1484.

Demirguc-Kint, A., Huizinga, H., 1999. Determinants of commercial bank interest margins and profitability: some international evidence. World Bank Economic Review 13(2), 379-408.

De Santis, R.A., Surico, P., 2013. Bank lending and monetary transmission in the euro area. Economic Policy 28(75), 423-457. 
Draghi, M., 2012. The monetary policy of the European Central Bank and its transmission in the euro area. Speech at Bocconi University, Milan.

Engle, R. F., Granger, C. W. J., 1987. Co-integration and error correction: representation, estimation, and testing. Econometrica 55(2), 251-276.

Flannery, M.J., James, C.M., 1984. The effect of interest rate changes on the common stock returns of financial institutions. The Journal of Finance 39, 1141-1153.

Hannan, T., Berger, A., 1991. The rigidity of prices: Evidence from banking industry. American Economic Review 81, 938-945.

Heffernan, S.A., 1997. Modelling British interest rate adjustment: An error correction approach. Economica 64, 211-231.

Kleimeier, S., Sander, H., 2004. Convergence in euro-zone retail banking? What interest rate pass-through tells us about monetary policy transmission competition and integration. Journal of International Money and Finance 23(3), 461-492.

Kleimeier, S., Sander, H., 2006. Expected versus unexpected monetary policy impulses and interest rate pass-through in euro-zone retail banking markets. Journal of Banking and Finance 30(7), 1839-1870.

Maudos, J., Guevara, J.F., 2004. Factors explaining the interest margin in the banking sectors of the European Union. Journal of Banking and Finance 28(9), 2259-2281.

Maudos, J., Solis, L., 2009. The determinants of net interest income in the Mexican banking system: an integrated model. Journal of Banking and Finance 33(10), 1920-1931.

Neri, S., 2014. The impact of the sovereign debt crisis on bank lending rates in the Euro-area. Bancaria 5, 1-34.

Parisi, L., Gianfrancesco, I., Giliberto, C., Giudici, P., 2015. Predicting bank interests when monetary rates are close to zero. Applied Mathematics, to appear.

Petris, G., Petrone, S., Campagnoli, P., 2009. Dynamic Linear Models with R. Springer, New York. 